\title{
Em busca de uma "poética diplomática"
}

\author{
João de Azevedo e Dias Duarte
}

Намpton, Timothy. Fictions of Embassy: literature and diplomacy in early modern Europe. Ithaca: Cornell University Press, 2012.

A trama de um dos últimos romances publicados em vida de Henry James, Os embaixadores (1903), gira em torno de uma missão "diplomática" frustrada. Lambert Strether, um norte-americano de meia-idade, é incumbido por sua noiva, a autoritária e rica viúva de Woolet, Nova Inglaterra, mrs. Newsome, de viajar a Paris para resgatar seu futuro enteado, o herdeiro Chad, supostamente envolvido em uma relação indecorosa com uma aristocrata europeia. Previsivelmente, o tiro sai pela culatra e é o "embaixador" Strether quem acaba seduzido pelos encantos do velho mundo, numa reviravolta que póe em risco suas pretensóes matrimoniais originais. Metaforicamente empregando aspectos da cultura política da diplomacia na construção do enredo de sua narrativa de ficção, Henry James, talvez inadvertidamente, dava continuidade a uma tradição de diálogo entre duas formas simbólicas iniciada na primeira modernidade, entre os séculos XV e XVII, na Europa.

A "interseção entre a história diplomática e a história da literatura" (p. 1), durante esse período, é precisamente o tema de Fictions of Embassy, terceiro livro de Timothy
Hampton, professor de literatura francesa e comparada da Universidade de Califórnia, Berkeley. Imerso na disciplina do novo historicismo, Hampton dedicou-se, em ensaios e livros anteriores, a explorar as relaçóes entre história, política e literatura no Renascimento europeu. Esse seu último livro - uma reedição do original publicado em 2009 continua no mesmo caminho, examinando as implicaçôes culturais da emergência de uma nova prática política, a diplomacia moderna.

Ainda que o termo "diplomacia" só tenha sido cunhado no século XVIII, a atividade diplomática precede em muito a primeira modernidade, remontando à Antiguidade. No entanto, "durante os séculos XV, XVI e XVII na Europa, a diplomacia sofreu uma série de transformaçôes sem precedentes, tanto práticas quanto teóricas, que fizeram dela um poderoso e importante elemento na política de Estado (statecraft)" (p. 1). A moldura mais geral na qual se encerraram essas inovaçóes - entre as quais se destacam a instituição do embaixador profissional, fixo ou "residente", e da negociação contínua em lugar dos "favoritos" reais e das embaixadas ad hoc medievais - foi o longo processo de constituição do sistema europeu de Estados soberanos. Tendo como marco histórico a chamada Paz de Westfalia de 1648, acordo que deu fim aos conflitos civil-religiosos no continente europeu, a nova ordem esta- 
tal emergente tanto requereu para sua conformação como tornou necessária para sua manutenção subsequente inéditos esforços sistemáticos de diplomacia. Esses requisitos práticos, por sua vez, geraram uma série de problemas - relativos à extraterritorialidade, aos limites da imunidade, às dinâmicas de delegação, representação e ratificação de acordos etc. —, cujas soluçôes teóricas, extrapolando a cultura retórica e moral do humanismo renascentista, ajudaram a delimitar, nos séculos XVII e XVIII, o campo das "relações internacionais", um espaço jurídico regido por negociaçôes contingentes entre Estados soberanos que se reconhecem como inimigos potenciais.

Fictions of Embassy não é, contudo, uma "história da diplomacia". Para as minúcias relativas à constituição da diplomacia moderna, Hampton apoia-se em uma vasta bibliografia, devidamente referida nas notas de rodapé. Como já afirmei, Fictions of Embassy ocupa-se antes da relação entre literatura e diplomacia — "meu foco é menos nos detalhes da história diplomática do que nos discursos que modelam a ação pública" (p. 7). Uma forma de compreender o objeto desse livro é visualizar a diplomacia "como um contexto para o estudo de uma série de grandes obras literárias” (p. 5). Desnecessário dizer que "contexto", neste caso, não é um dado sólido e fixo (uma "infraestrutura” rígida) do qual se deduz o texto literário, mas sim, ele próprio, um "texto", até certo ponto aberto, requerendo também uma leitura, da mesma forma que o seu análogo literário. À maneira novo-historicista, Hampton interessa-se pelos processos dinâmicos de conflito e negociação entre formas simbólicas que informam a cultura; o que faz dele, o analista e crítico literário, também uma espécie de diplomata, em busca do que ele mesmo define - ecoando a formulação de Stephen Greenblatt do new historicism como uma "poética da cultura" — como uma "poética diplomática", i.e.: "tanto uma maneira de ler literatura que seja sensível (attuned) à sombra do Outro na fronteira da comunidade nacional, quanto uma maneira de ler a diplomacia que leve em consideração as suas dimensōes fictícias e linguísticas” (p. 2-3).

Vista de uma tal perspectiva, a relação entre literatura e diplomacia na primeira modernidade aparece não como meramente temática ou unidirecional, mas sim como uma relação estrutural e de mão dupla. Mais do que simplesmente fornecer um repertório de materiais (cenas, personagens e tópicos) a escritores de peças, poemas e ensaios (o que não deixava de fazer), a diplomacia oferecia à literatura imaginativa um análogo discursivo, com consequências importantes para ambas. Há semelhanças entre a palavra do diplomata e a palavra do poeta, sugere Hampton, que insiste ser "a diplomacia [...] o ato político simbólico por excelência” (p. 5 - ênfase no original), tanto por sua natureza semiótica (sua relação íntima com a produção e a interpretação de signos, gestos e palavras), como pelo fato de que é também uma prática escrita, conscientemente envolvida com questóes de representação, narrativa, retórica e autoridade textual. Ademais, na medida em que depende da invenção de "ficçóes jurídicas" — tal como aquela que determina a "imunidade" do diplomata em 
missão, como se ele estivesse em seu próprio país - , a diplomacia implica ainda, à semelhança de textos literários, atos de "produção de ficção" (fiction making) - "por "produção de ficção' eu entendo a criação de textos que definem para si mesmos um modo de representação que náo pretende um acesso direto à verdade teológica ou epistemológica" (p. 10). Sendo, então, "uma forma de ação política [...] profundamente estruturada pela dinâmica da significaçáo", conclui Hampton, "a diplomacia oferece uma analogia poderosa para com a prática de construção de sentido a que chamamos literatura" (p. 10).

Hampton não está dizendo que a diplomacia e a literatura sejam práticas de representação indistintas, mas sim que, nesse período crítico da modernidade europeia, elas se articulavam de maneiras variadas e complexas, modelando-se mutuamente. "A nova ferramenta política da diplomacia e a cultura emergente da literatura secular modelam-se uma a outra de maneiras importantes": de um lado, "os textos literários fornecem um terreno único e privilegiado para estudar as linguagens da diplomacia", dando voz a certas ansiedades e tensóes não explícitas da política diplomática, do outro, "a cultura diplomática desempenha um papel dinâmico na história literária, na invenção de novas formas, convenções e gêneros literários" (p. 2). Uma das conclusóes importantes do livro é que, exatamente por causa de sua proximidade, a diplomacia acabou por servir como um contramodelo para a literatura de ficção, ajudando-a, por oposição, a definir sua própria voz.

Os capítulos - cuja sucessão segue frouxamente a ordem cronológica, iniciando-se ao final do século XV e terminando ao final do século XVII, com uma coda sobre o século XIX - dividem-se em três seçôes, cada uma abordando questóes em torno a algum tema ligado à atividade diplomática, respectivamente: negociação, mediação e representação. Com leituras de Guicciardini, Maquiavel, Thomas Morus, Rabelais, Tasso e Montaigne, os capítulos 1 e 2 examinam a relação entre a diplomacia e a cultura do humanismo renascentista, no âmbito da qual aquela recebe as suas primeiras formulaçóes teóricas, explorando as tensōes entre as expectativas éticas do humanismo e as contingências práticas, nem sempre "honoráveis", das "úteis" negociaçôes diplomáticas. Esses capítulos iniciais estabelecem também um padrão analítico para a interpretação da interseção entre teoria diplomática e literatura de ficção. De início, delimita-se um conjunto específico de problemas ligados à atividade diplomática (nesse caso, questóes relativas ao caráter do embaixador e à extensão de sua liberdade no uso da linguagem no contexto da negociação diplomática) a partir de textos de teoria política e diplomática para, em seguida, discutir o modo como tais problemas são tratados em textos de caráter ficcional, com atenção para seus aspectos linguísticos e retóricos e para tensóes ideológicas ocultas.

Já nos primeiros capítulos, Hampton chama a atenção para uma tensão crescente entre os mundos da política e da literatura de ficção; uma tensão que emerge, nos textos, por meio da representaçáo de cenas de diplomacia frustrada, uma recorrência nas obras analisadas no livro. Na leitura de Hampton, 
a representação literária da diplomacia (e de seu fracasso) serve como um momento crítico, um momento privilegiado náo apenas para a reflexão sobre ansiedades e conflitos político-sociais não explícitos, mas também para uma autorreflexão, da qual se origina um estranhamento em relação à política. $\mathrm{Na}$ medida em que "a negociação diplomática é vista como a sinédoque da retórica política pública”, argumenta Hampton, então, "é mostrando o colapso da diplomacia que as obras literárias podem reivindicar sua própria autoridade linguística e genérica" (p. 34). Esse movimento duplo de representaçáo dos limites da diplomacia e de autoafirmação discursiva, envolvendo, com frequência, a invenção (ou reinvenção) de novas formas literárias, repete-se ao longo dos capítulos - "por meio do fracasso diplomático, a literatura cria o espaço de seu desdobramento" (p. 186).

Os capítulos 3 e 4 abordam a épica, um dos gêneros narrativos mais importantes do período, a partir de questóes relativas ao espaço: deslocamento, extraterritorialidade e encontros entre europeus e não europeus. Por meio de leituras originais de Jerusalem libertada, de Torquato Tasso, e Os lusíadas, de Luís de Camôes, Hampton explora a tensão entre as convençóes diplomáticas e os ideais heroicos que informavam o gênero. Escrevendo no final do século XVI, num momento em que a cultura retórica e moral do humanismo encontrava-se sob a pressão da nova Igreja militante da Contrarreforma, ambos os autores empregaram a linguagem diplomática para repensar o gênero épico. Negociando uma identidade poética e epis- temológica com as formas rivais da épica clássica, da historiografia e das narrativas romanescas, Jerusalém libertada e Os lusíadas tematizam a caducidade dos códigos cavalheirescos medievais e a emergência de um mundo pós-heroico - o mundo do direito internacional, do mercantilismo e das burocracias diplomáticas.

Finalmente, os três últimos capítulos dáo conta de questóes ligadas ao papel da nova ferramenta política da diplomacia no processo concomitante de constituição dos Estados nacionais e do estabelecimento de um sistema jurídico internacional, tais como: o reconhecimento político da soberania de novas entidades políticas por meio da recepção e do envio de embaixadas; a transição do antigo quadro teológico-moral do ius gentium (a lei das naçóes) para o novo quadro secular do direito codificado, ius inter gentes (a lei entre naçóes) nas relaçôes internacionais; e a "domesticação" da aristocracia por meio de sua conversão em uma casta burocrática de diplomatas profissionais. A forma literária escolhida para a discussão dessas questóes é o drama, a forma privilegiada nas cortes europeias do século XVII. As análises de Hampton de três grandes tragédias, Nicomède, de Pierre Corneille, Hamlet, de William Shakespeare, e Andromaque, de Jean Racine, mostram como a tragédia, mais do que qualquer outro gênero, tematizou a diplomacia de modo a expor o caráter instável e frágil da nova ordem política. Ao mesmo tempo que projeta uma modernidade pós-heroica — de paz e negociação civilizada entre naçôes em lugar do amor obsessivo e da violência privada pré-estatal —, a 
tragédia conjura essa imagem, trazendo ao palco o desejo e a vingança recalcados que póem em risco as próprias instituiçóes que vislumbra.

Fictions of Embassy é, sem dúvida, um livro inovador e instigante, que enriquece e complexifica nosso entendimento de um período crítico da história ocidental, por meio de uma abordagem audaciosa que combina enorme erudição histórica e sensibilidade crítica para explorar o cânon literário da primeira modernidade. Trata-se de um livro denso que, a despeito de seu tamanho diminuto (230 páginas), é capaz de cobrir uma extensão impressionante de tópicos, oferecendo leituras originais de um conjunto náo menos impressionante de obras. No entanto, é possível que, ao fim da leitura, o leitor se sinta um tanto ou quanto frustrado com o resultado final de um projeto que lhe parecia de início tão promissor e excitante. É que, em seu afã para persuadir o leitor do papel histórico da diplomacia como o agente decisivo de inovação na história literária, Hampton acaba por, em certos momentos, forçar demais seu material, gerando conclusóes apressadas que produzem no leitor o efeito contrário ao esperado. Tenho dúvidas, por exemplo, se "a poética de Tasso e o autorretrato de Montaigne" são mesmo "os subprodutos de suas próprias tentativas de reinventar (reimagine) a ação política por meio de uma reflexão sobre a diplomacia” (p. 71), como Hampton sugere; ou se “a diplomacia é um elemento estruturante central no poema” de Camóes (p. 101) ou no Hamlet, de Shakespeare (p. 144-162); ou ainda se "Corneille é o primeiro grande dra- maturgo da geopolítica” (p. 122). Eis alguns casos nos quais menos entusiasmo e mais prudência seriam recomendáveis. Ademais, para alguém tão interessado na intersecção e mútua influência entre diplomacia e literatura, Hampton dá pouca atenção aos tratados diplomáticos, utilizando-os apenas de forma subsidiária à leitura das obras de ficção, e nem sequer aborda a carta diplomática, provavelmente o gênero mais importante para a prática da diplomacia na primeira modernidade. Faz falta também uma abordagem mais cuidadosa acerca das transformações ocorridas na diplomacia ao longo do tempo, em especial, na transição da Idade Média à primeira modernidade. Por fim, um diálogo com obras que trataram de usos mais metafóricos e menos literais da diplomacia na literatura, como o brilhante La diplomatie de l'esprit, de Marc Fumaroli, poderia ter sido interessante, sobretudo para a compreensão da influência da cultura diplomática sobre o gênero maior da modernidade, o romance. Em que pesem essas ressalvas, Fictions of Embassy é ainda um livro altamente recomendável a todos aqueles interessados na literatura ou história intelectual da primeira modernidade.

O livro é concluído com um breve posfácio, contendo um comentário sobre $O$ vermelho e o negro, de Stendhal, com o intuito de apontar para a continuidade da história traçada até ali. Se a história narrada em Ficitons of Embassy foi "primordialmente uma história da cultura aristocrática”, a conclusão volta-se rapidamente para "uma consideração acerca de como os temas diplomáticos são transmutados quando apropriados pelo 
gênero dominante da modernidade burguesa - o romance" (p. 190). Numa leitura perspicaz, ainda que breve, Hampton argumenta que é na obra de Stendhal que a carreira literária moderna da diplomacia toma um rumo decisivo (é possível, porém, que uma leitura do livro supracitado de Marc Fumaroli o desmentisse, antecipando essa virada). $O$ vermelho e o negro, sugere ele, marca o momento em que a diplomacia deixa de ser "a sinédoque da retórica política pública" ao mesmo tempo o modelo dialógico rival e prenúncio da política burocrática moderna - que havia sido para a literatura imaginativa durante a primeira modernidade.
Aliviada de seu peso político, apartada do mundo dos grandes dramas da negociação entre as naçôes, a diplomacia converte-se numa metáfora social para negociar as intrigas que dáo forma aos pequenos (porém profundos) dramas cotidianos, dos costumes, da consciência moral, do refinamento estético e da felicidade (ou infelicidade) conjugal, nos quais estáo envolvidos os Julien Sorel, Lambert Strether e as mrs. Newsome, de Woolet, Nova Inglaterra.

${ }^{*}$ Doutor em história social da cultura pela Pontifícia Universidade Católica do Rio de Janeiro, bolsista de pós-doutorado pelo PNPD Capes. Rio de Janeiro, RJ, Brasil. E-mail: jadduarte@gmail.com. 